\title{
Postnatal Changes in Pyridine Nucleotides in Rat Hepatocytes: Composition and $\mathrm{O}_{2}$ Dependence
}

\author{
TAK YEE AW \\ Department of Physiology and Biophysics, Louisiana State University Medical Center \\ Shreveport, Louisiana 71130
}

\begin{abstract}
Postnatal changes in pyridine nucleotide concentration, composition, and oxidation-reduction characteristics were studied in liver cells from neonatal (newborn, $d$ 4 and $\mathrm{d} 8$ ) and adult rats to determine the development of hepatic pyridine nucleotide status and $\mathrm{O}_{2}$ dependence of oxidation of reducing equivalents. The results show that the total pyridine nucleotide concentrations in newborn and 4-d-old rat liver were low (30\%) but increased to near adult values $(80 \%)$ by $d 8$ postpartum. Analyses of the cellular distribution of NAD ${ }^{+}$, NADH, NADP ${ }^{+}$, and NADPH reveal that the reduced forms (NADH plus NADPH) accounted for over $50 \%$ of the total in the newborn and 4-dold rats compared to $30 \%$ in adult animals. This relatively higher reductive capacity in hepatocytes of younger rats was largely the result of a significantly higher proportion of NADPH in these cells. Examination of the NADPH/ $\mathrm{NADP}^{+}$and NADH/NAD ${ }^{+}$ratios show that they occur in an inverse relationship with postnatal age; the NADPH/ $\mathrm{NADP}^{+}$ratio was high at birth and decreased with age, whereas the reverse pattern was found for the NADH/ $\mathrm{NAD}^{+}$ratio. The result, that NADPH represents a significant percentage of the total pyridine nucleotides in neonatal cells in the early postnatal period, is consistent with a higher demand for NADPh for biosynthetic activities in association with tissue growth. A high NADPH concentration coupled with a low NADH concentration in these cells is further consistent with the finding that succinate is a preferred substrate for newborn respiratory function so as to spare NADH for transhydrogenation to NADPH. The half-maximal oxidation of pyridine nucleotides in cells from newborn rats occurred at $0.49 \mu \mathrm{M} \mathrm{O}_{2}$, as compared to 1.2 and $4.0 \mu \mathrm{M} \mathrm{O}_{2}$ in cells from 4-d-old and adult rats, respectively. Direct comparison of the $\mathrm{O}_{2}$ dependencies of pyridine nucleotides at different ages with those of cytochrome $c+c_{1}$ demonstrates that the oxidation of pyridine nucleotides occurs in concert with the expression of mitochondrial respiratory components during development. (Pediatr Res 30: 112-117, 1991)
\end{abstract}

\section{Abbreviations}

$\mathbf{P}_{\text {50, half-maximal }}$

The transition from the neonate to the adult is associated with dramatic increases in oxidative metabolism and in tissue growth. Accompanying these developmental events are respective increases in cellular respiration and biosynthetic activities and the

Received October 30, 1990; accepted February 22, 1991.

Correspondence and reprint requests: Dr. Tak Yee Aw, Department of Physiology and Biophysics, LSU Medical Center, 1501 Kings Highway, Shreveport, LA 71130 .

Supported by a grant from the Sudden Infant Death Syndrome Alliance. associated greater demand for oxidizable substrates and reducing equivalents. In liver, the age-dependent increase in cellular respiration is attained by marked changes in the composition and contents of the enzymes of the respiratory systems (1-5) and by selective use of specific respiratory substrates $(6,7)$. We recently found that hepatocytes from newborn rats preferentially use succinate for cell respiration compared to a variety of other carbohydrate or amino acid substrates $(6,7)$. These results suggest that oxidation of NADH is limited during the late fetal and early perinatal phases of development (8). The relatively slower ontogenic development of pyruvate dehydrogenase activity compared to other mitochondrial enzymes (9) is consistent with a limited utilization of glucose or lactate for energy production $(8,10)$. Together, the limitation of $\mathrm{NAD}^{+}$-linked oxidations and the selective oxidation of succinate as an alternate fuel in neonatal cells would spare NADH to supply NADPH for enhanced biosynthetic processes that are associated with increased tissue growth during this period. Consequently, the pyridine nucleotide status during development will be defined by specific metabolic requirements at the different ages, and perturbations of this status could have profound effects on the availability of reducing equivalents for specific oxidative or biosynthetic processes.

Although numerous studies have demonstrated marked changes in the adenine nucleotide pool sizes and the mitochondrial-to-cytosolic distribution of adenine nucleotides within hours after birth (11-13), little is known of the postnatal changes in the pyridine nucleotide status. To better understand the agedependent variations in pyridine nucleotide status, we have examined the postnatal changes in 1 ) pyridine nucleotide concentration and distribution of oxidized and reduced forms, 2) ratios of NADPH/NADP ${ }^{+}$and NADH/NAD ${ }^{+}$, and 3) $\mathrm{O}_{2}$ requirement for pyridine nucleotide oxidation in hepatocytes from rats of different ages. The results show that neonatal hepatocytes have a lower total pyridine nucleotide content, a higher reductive capacity that is largely the result of a greater proportion of $\mathrm{NADPH}$, a higher NADPH/NADP ${ }^{+}$ratio, and a lower $\mathrm{O}_{2}$ dependence of oxidation that is similar to that of the mitochondrial cytochromes. The higher reductive-to-oxidative capacity and the lower $\mathrm{O}_{2}$ requirement in neonatal cells suggest that control mechanisms that are associated with pyridine nucleotide status will be qualitatively and quantitatively distinct from adult hepatocytes.

\section{MATERIALS AND METHODS}

Materials. The following chemicals were purchased from Sigma Chemical Co., St. Louis, MO: collagenase IV, deoxyribonuclease (DNAse) I, $N$-2-hydroxyethylpiperazine- $N^{\prime}$-2-ethanesulfonic acid, $\gamma$ globulin, NAD ${ }^{+}, \mathrm{NADP}^{+}, \mathrm{NADH}$, and NADPH. Other chemicals were of reagent grade and were purchased from local sources.

Cell isolation. Rats (10-15 pups, $22 \mathrm{~d}$ at term) were delivered by natural birth. Rat pups were removed from their mothers (Sprague-Dawley females, $250 \mathrm{~g}$, from Animal King Laborato- 
ries, Oregon, WI) within either $12 \mathrm{~h}, 4 \mathrm{~d}$, or $8 \mathrm{~d}$ after birth. The three postnatal age groups were selected to correspond to the newborn (12 h), the doubling (4d), and the tripling ( $8 \mathrm{~d})$ of the growth rate of the animals (14). For each age group, neonatal rats were killed by decapitation and livers were surgically removed, weighed, sliced, and washed free of excess blood with $\mathrm{Ca}^{2+}$-free Hanks' buffer, pH 7.4. Hepatocytes were isolated according to a minor modification of the method of Devirgiliis et al. (15). Briefly, sliced liver tissues were incubated and collagenase $(1 \mathrm{mg} / \mathrm{mL})$ and DNAse $(0.05 \mathrm{mg} / \mathrm{mL})$ at $37^{\circ} \mathrm{C}$ under $95 \%$ $\mathrm{O}_{2}, 5 \% \mathrm{CO}_{2}$ atmosphere for successive 15 -min incubations with three changes of fresh digestion medium. Cells were filtered through nylon sizing mesh (size 103), washed with modified Krebs-Henseleit buffer, pH $7.4(6,16,17)$, and then purified on $30 \%$ Percoll in Krebs-Henseleit. Adult hepatocytes were prepared as previously described (17). Hepatocytes from neonatal and adult rats were assessed for viability by their ability to exclude $0.2 \%$ trypan blue, and, for neonatal cells, contamination by erythrocytes and hematopoietic cells was determined by morphologic differences in appearance under a light microscope. Typically, this isolation and purification procedure yields $\sim 90 \%$ hepatocytes with less than $10 \%$ contamination by nonparenchymal and hematopoietic cells, in agreement with previous studies $(6,15)$. The cells from all age groups were maintained at $20^{\circ} \mathrm{C}$ in a gyrating water bath for 5 to $6 \mathrm{~h}$ without loss of viability.

Incubations and sampling for pyridine nucleotide determinations. Incubations $\left(1.5 \times 10^{6}\right.$ cells $/ \mathrm{mL}$ for neonatal or $1.0 \times 10^{6}$ cells $/ \mathrm{mL}$ for adult hepatocytes) were carried out at $37^{\circ} \mathrm{C}$ in rotating round-bottom flasks in modified Krebs-Henseleit buffer containing $25 \mathrm{mM} N$-2-hydroxyethylpiperazine- $N^{\prime}$-2-ethanesulfonic acid $\mathrm{pH} 7.4$, as previously described $(6,16,17)$. After 30 min of incubation, samples were removed and treated with $3 \mathrm{M}$ perchloric acid $(0.5 \mathrm{~mL}$ per $1-\mathrm{mL}$ incubation mixture). Denatured proteins were removed by centrifugation and the acid supernatants were placed on ice for subsequent determination of oxidized pyridine nucleotides $\left(\mathrm{NAD}^{+}\right.$and $\left.\mathrm{NADP}^{+}\right)$. For measurements of reduced pyridine nucleotides (NADH and NADPH), samples $(0.5 \mathrm{~mL})$ were removed and treated with $0.1 \mathrm{~mL}$ of 0.5 $\mathrm{M}$ potassium hydroxide containing $50 \%$ ( $\mathrm{vol} / \mathrm{vol}$ ) ethanol and $35 \%$ (wt/vol) cesium chloride. The treated samples were immediately cooled on ice and centrifuged to remove insoluble material.

Spectrophotometry. The $\mathrm{O}_{2}$ dependence of oxidation-reduction changes of pyridine nucleotides and cyrochrome $c+c_{1}$ were determined by dual-wavelength spectrophotometry on an Aminco DW 2a spectrophotometer (SLM Instruments, Inc., Urbana, IL) equipped with a $3.9-\mathrm{cm}$ light path incubation vessel $(18,19)$. Cells were maintained in suspension by gentle stirring with a magnetic stirrer, and $\mathrm{O}_{2}$ concentrations in solutions were measured by an $\mathrm{O}_{2}$ electrode inserted through the cover of the incubation vessel. The gaseous phase was flushed continuously with prepurified argon $\left(<0.001 \% \mathrm{O}_{2}\right)$ delivered via a low $\mathrm{O}_{2}-$ permeability butyl rubber tubing. Oxidation-reduction changes for pyridine nucleotides and cytochrome $c+c_{I}$ were measured with the respective wavelength pairs, $340-375$ and $550-540 \mathrm{~nm}$.

Analytical assays. Perchloric acid extracts of cell incubation were neutralized with $10 \mathrm{M} \mathrm{KOH}$ and the supernatants were analyzed for $\mathrm{NAD}^{+}$and $\mathrm{NADP}^{+}$concentrations by HPLC (20). The concentrations of NADH and NADPH were similarly analyzed by HPLC in an ethanolic extracts of cell incubations (20). Total cell protein contents were determined on the acid precipitable fractions by the method of Bradford (21) using the protein dye-reagent concentration from Bio-Rad Laboratories (Richmond, CA) and bovine $\gamma$ globulins as standard. Statistical analyses were performed using the $t$ test.

\section{RESULTS}

Hepatic pyridine nucleotide concentrations as function of age. This study was designed to examine the postnatal changes in hepatic pyridine nucleotide status and the $\mathrm{O}_{2}$ requirement for oxidation of reducing equivalents. Studies were performed using freshly isolated hepatocytes from neonatal (newborn and 4- and 8-d-old) and adult rats, and the results are presented in Table 1. The adult values were comparable to those reported previously (20). The total concentrations of pyridine nucleotides in the younger age groups (newborn and 4-d-old rats) were low (34 and $30 \%$ of adult values, Table 1), but increased to near adult levels ( $80 \%$, Table 1 ) by $\mathrm{d} 8$, which would parallel the age-dependent increase in oxidative metabolism. Even when the values were expressed on per mg protein bases (Table 1), the total concentrations at $12 \mathrm{~h}$ and $4 \mathrm{~d}$ after birth were, respectively, 49 and $43 \%$ lower than adult values, indicating that the pyridine nucleotide content of neonatal hepatocytes during early postnatal development is quantitatively distinct from that of adult cells.

Distribution of oxidized and reduced pyridine nucleotides. To determine whether the compositions of oxidized and reduced forms are altered during postnatal development, we analyzed the concentrations of the individual components $\left(\mathrm{NAD}^{+}, \mathrm{NADH}\right.$, $\mathrm{NADP}^{+}$, and NADPH) in cells from rats of different ages. The results in Table 1 show that the oxidized and reduced nucleotides in cells from newborn and-4-d-old rats were to varying degrees, significantly lower than adult values. Examination of $\mathrm{NADH}$ content shows that the concentration in cells from newborn rats was about $10 \%$ of adult concentrations, doubled by $\mathrm{d} 4$, and reached adult levels by $\mathrm{d} 8$ (Table 1 ). The hepatic NADPH concentration at birth was one half that of the adult values and did not significantly change by d 8 (Table 1 ). In comparison, the age-dependent changes in oxidized pyridine nucleotides followed a pattern that is similar to that of the reduced nucleotides. The $\mathrm{NAD}^{+}$level was $30 \%$ at birth but reached adult levels by $\mathrm{d} 8$ postpartum, whereas the $\mathrm{NADP}^{+}$concentration was low (15\%) at birth and remained at $50 \%$ of adult levels by d 8 (Table 1). These results show that marked increases in content and substantial changes in the oxidized and reduced pyridine nucleotide composition occur in rat liver from birth to adult.

To determine the relative contribution of the individual nucleotides to the total pool size, the content of each component was expressed as a percentage of the total pyridine nucleotide concentration for the different ages. The results show that the distribution pattern varied greatly among the age groups. Notably, significantly higher proportions of reduced nucleotides were found in cells from newborn and 4-d-old rats than from 8-d-old or adult animals (Fig. 1). The sum of NADH and NADPH in cells from the younger rats accounted for greater than $50 \%$ of the total nucleotides (Fig. 1), indicating that a greater reductiveto-oxidative capacity exists at the younger ages. The results additionally show that NADPH constituted $95 \%$ of the total reduced nucleotides at birth and decreased proportionately with increasing age of the rats (Fig. 1). These results therefore suggest that the relatively higher reductive capacity in neonatal liver cells during the early period of postnatal development can largely be attributed to NADPH. This is consistent with a higher demand for NADPH for biosynthetic processes associated with tissue growth during this critical period.

Postnatal changes in pyridine nucleotide redox status. Because significant differences in pyridine nucleotide content and distribution were found at various ages, age-dependent differences may also occur in the cellular NADPH/NADP ${ }^{+}$and NADH/ $\mathrm{NAD}^{+}$redox status. To examine this, the ratios of the two cellular pyridine nucleotide redox couples, NADPH/NADP ${ }^{+}$and $\mathrm{NADH} / \mathrm{NAD}^{+}$, were determined. The results in Figure 2 show that in the newborn and 4-d-old rats the NADPH/NADP ${ }^{+}$ratio was high (7.5) and decreased in an age-dependent manner to adult values $(2.0)$. In contrast, the $\mathrm{NADH} / \mathrm{NAD}^{+}$ratio was low in the newborn (0.07) and increased to adult status $(0.2)$ by $\mathrm{d} 8$ (Fig. 2). These results demonstrate that the pyridine nucleotide redox potential alters dramatically with postnatal age and parallels the changes in concentration and distribution of the individual components. The results further show that the changes in the 
Table 1. Pyridine nucleotides in isolated hepatocytes from rats of different postnatal ages*

\begin{tabular}{|c|c|c|c|c|}
\hline & \multicolumn{4}{|c|}{ Postnatal ages } \\
\hline & Newborn $(n=5)$ & Day $4(n=3)$ & Day $8(n=3)$ & Adult $(n=5)$ \\
\hline \multicolumn{5}{|l|}{ Total PN } \\
\hline $\mathrm{nmol} / \mathrm{mg}$ protein & $5.86 \pm 0.13 \dagger$ & $5.18 \pm 0.50 \dagger$ & $10.3 \pm 0.15$ & $11.8 \pm 1.93$ \\
\hline \multicolumn{5}{|l|}{$\mathrm{NADH}$} \\
\hline $\mathrm{nmol} / 10^{6}$ cells & $0.18 \pm 0.03 \dagger \ddagger$ & $0.46 \pm 0.03 \dagger$ & $1.86 \pm 0.13$ & $1.65 \pm 0.07$ \\
\hline \multicolumn{5}{|l|}{$\mathrm{NAD}^{+}$} \\
\hline $\mathrm{nmol} / 10^{6}$ cells & $2.75 \pm 0.12 \dagger$ & $2.28 \pm 0.80 \dagger$ & $8.75 \pm 0.60$ & $8.48 \pm 1.20$ \\
\hline $\mathrm{nmol} / \mathrm{mg}$ protein & $2.50 \pm 0.11 \dagger$ & $2.07 \pm 0.72 \dagger$ & $6.48 \pm 0.44 \|$ & $5.31 \pm 0.75$ \\
\hline \multicolumn{5}{|l|}{ NADPH } \\
\hline $\mathrm{nmol} / 10^{6}$ cells & $3.10 \pm 0.20 \dagger$ & $2.42 \pm 0.41 \dagger$ & $2.61 \pm 0.30 \dagger$ & $5.36 \pm 0.50$ \\
\hline $\mathrm{nmol} / \mathrm{mg}$ protein & $2.82 \pm 0.18 \S$ & $2.20 \pm 0.37 \dagger$ & $1.93 \pm 0.23 \dagger$ & $3.35 \pm 0.31$ \\
\hline \multicolumn{5}{|l|}{$\mathrm{NADP}^{+}$} \\
\hline $\mathrm{nmol} / 10^{6}$ cells & $0.44 \pm 0.08 \dagger$ & $0.54 \pm 0.13 \dagger$ & $1.33 \pm 0.20 \dagger$ & $2.86 \pm 0.09$ \\
\hline
\end{tabular}

* The concentrations of $\mathrm{NAD}^{+}$and $\mathrm{NADP}^{+}$were determined in perchloric acid extracts and NADH and NADPH in ethanolic KOH extracts (20). Results are expressed as nmol per $10^{6}$ cells or as nmol per $\mathrm{mg}$ protein using the measured protein content per $10^{6}$ cells: $1.1 \mathrm{mg}$ for newborn and 4-d-olds, $1.35 \mathrm{mg}$ for 8-d-olds, and $1.6 \mathrm{mg}$ for adult. Values given are the mean \pm SEM of the number of cell preparations in parentheses.

$\dagger p<0.005$ for comparisons with adult.

$\ddagger p<0.005$ for comparison of newborn $v s$ all ages.

$\S p<0.01$ for comparisons with adult.

$\| p<0.05$ for comparisons with adult.

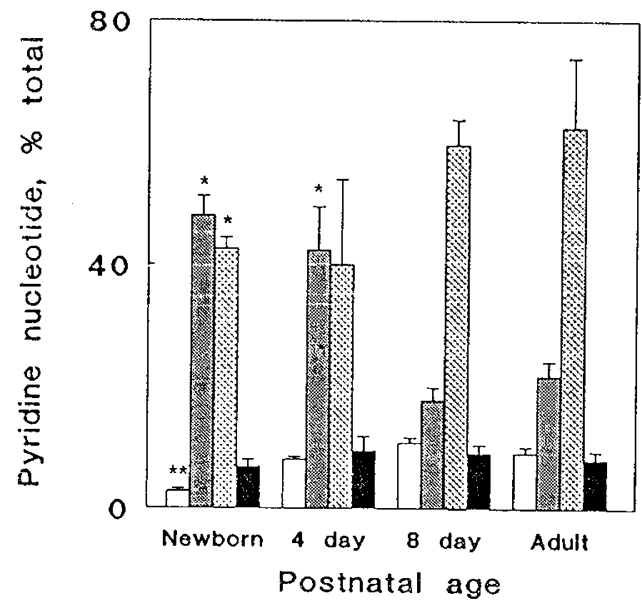

Fig. 1. Distribution of pyridine nucleotides as a function of postnatal ages. The concentrations of $\mathrm{NAD}^{+}$(圈), $\mathrm{NADP}^{+}(\mathbf{\square}), \mathrm{NADPH}$ (圆), and $\mathrm{NADH}(\square)$ were determined in cells from different postnatal ages by HPLC (20). Results are expressed as a percentage of total pyridine nucleotides, and values represent the mean \pm SEM of five cell preparations from newborn and adult rats and three cell preparations from 4and 8-d-old rats. ${ }^{*}, p<0.005$ for comparisons with 8-d-old and adult rats ${ }^{* *}, p<0.005$ for comparison of newborn $v s$ all ages.

$\mathrm{NADPH} / \mathrm{NADP}^{+}$and $\mathrm{NADH} / \mathrm{NAD}^{+}$couples during development are inversely related, thus emphasizing a potential difference in the role that each redox couple may play in regulation of metabolism at the various ages. It can be additionally noted that the marked difference in the redox potential contributed by the NADPH/NADP ${ }^{+}$or NADH/NAD ${ }^{+}$couples becomes more dramatic when their relationship is expressed in terms of the two reduced forms, NADPH/NADH (Fig. 2). These results therefore suggest that regulation of metabolism by pyridine nucleotide status in neonatal tissues would be distinct from that in adult tissues, and that perturbations in the status of either redox couple will result in differential effects on neonatal and adult metabolism.

Oxidation-reduction of pyridine nucleotides. Earlier studies with isolated hepatocytes from newborn rats showed that the $\mathrm{O}_{2}$

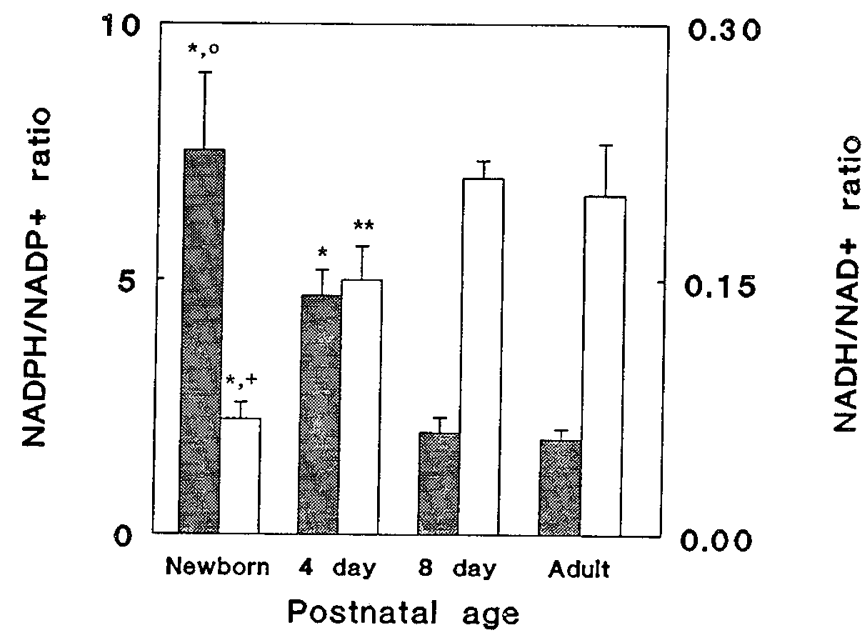

Fig. 2. Postnatal changes in NADPH/NADP ${ }^{+}$and NADH/NAD redox ratios. The concentrations of oxidized and reduced pyridine nucleotides were determined by HPLC (20), and the results are expressed as $\mathrm{NADPH} / \mathrm{NADP}^{+}$(飡) and NADH/NAD ${ }^{+}(\square)$, ratios as a function of postnatal ages. ${ }^{*}, p<0.005$ for comparisons with 8 -d-old and adult rats. ${ }^{* *}, p<0.05$ for comparison of 4- $v$ s 8-d-old rats.,$+ p<0.005$; $0, p<$ 0.01 for comparison of newborn $v s 4$-d-old rats.

concentration required for maximal mitochondrial function is low $(6,7)$. Because the oxidation of reducing equivalents is closely related to oxidation of mitochondrial cytochromes, the $\mathrm{O}_{2}$ concentration requirement for oxidation of pyridine nucleotides may also be small. To examine this, the oxidation-reduction changes of pyridine nucleotides as a measure of the $\mathrm{O}_{2}$ dependence of mitochondrial oxidation of reducing equivalents were determined. Because the $\mathrm{O}_{2}$ consumption rates of neonatal cells are very low in the absence of added substrates (6) (Table 2) and are sensitive to succinate (6), the $\mathrm{P}_{50}$ value was measured in the presence of $1.5 \mathrm{mM}$ succinate. The results in Figure 3A show that the $\mathrm{P}_{50}$ value for oxidation of pyridine nucleotides in hepatocytes from newborn rats was low $\left(0.49 \mu \mathrm{M} \mathrm{O}_{2}\right)$, in a range similar to that found for isolated mitochondria $(7,22)$ and for neonatal mitochondrial cytochromes $(6,7)$ (Fig. $3 B$ ). Moreover, the oxidation of pyridine nucleotides varied with cellular $\mathrm{O}_{2}$ 
Table 2. Comparison of $\mathrm{O}_{2}$ consumption rates in isolated hepatocytes from newborn, 4-d-old, and adult rats in the absence or presence of succinate*

\begin{tabular}{cccc}
\hline & \multicolumn{2}{c}{$\mathrm{O}_{2}$ consumption rate $\left(\mathrm{nmol} / 10^{6}\right.$ cells $\left./ \mathrm{min}\right)$} & \multicolumn{2}{c}{$\begin{array}{c}\text { Ratio of }+ \text { succinate/ } \\
\text { Age }\end{array}$} & -succinate \\
\hline Newborn $(n=7)$ & $0.50 \pm 0.06$ & $+1.5 \mathrm{mM}$ succinate & 14.4 \\
4-d-old $(n=4)$ & $1.21 \pm 0.05$ & $11.9 \pm 1.0$ & 9.8 \\
Adult $(n=3)$ & $24.3 \pm 1.1$ & $36.5 \pm 1.7$ & 1.5 \\
\hline
\end{tabular}

${ }^{*} \mathrm{O}_{2}$ consumption was measured polarographically with an $\mathrm{O}_{2}$ electrode. Results are expressed as $\mathrm{nmol} / 10^{6}$ cells/min or as ratio of rates in the presence or absence of $1.5 \mathrm{mM}$ succinate. Values given are the mean \pm SEM of the number of cell preparations in parentheses. For newborn and 4d-old rats, livers from $10-15$ pups were pooled for one cell preparation.
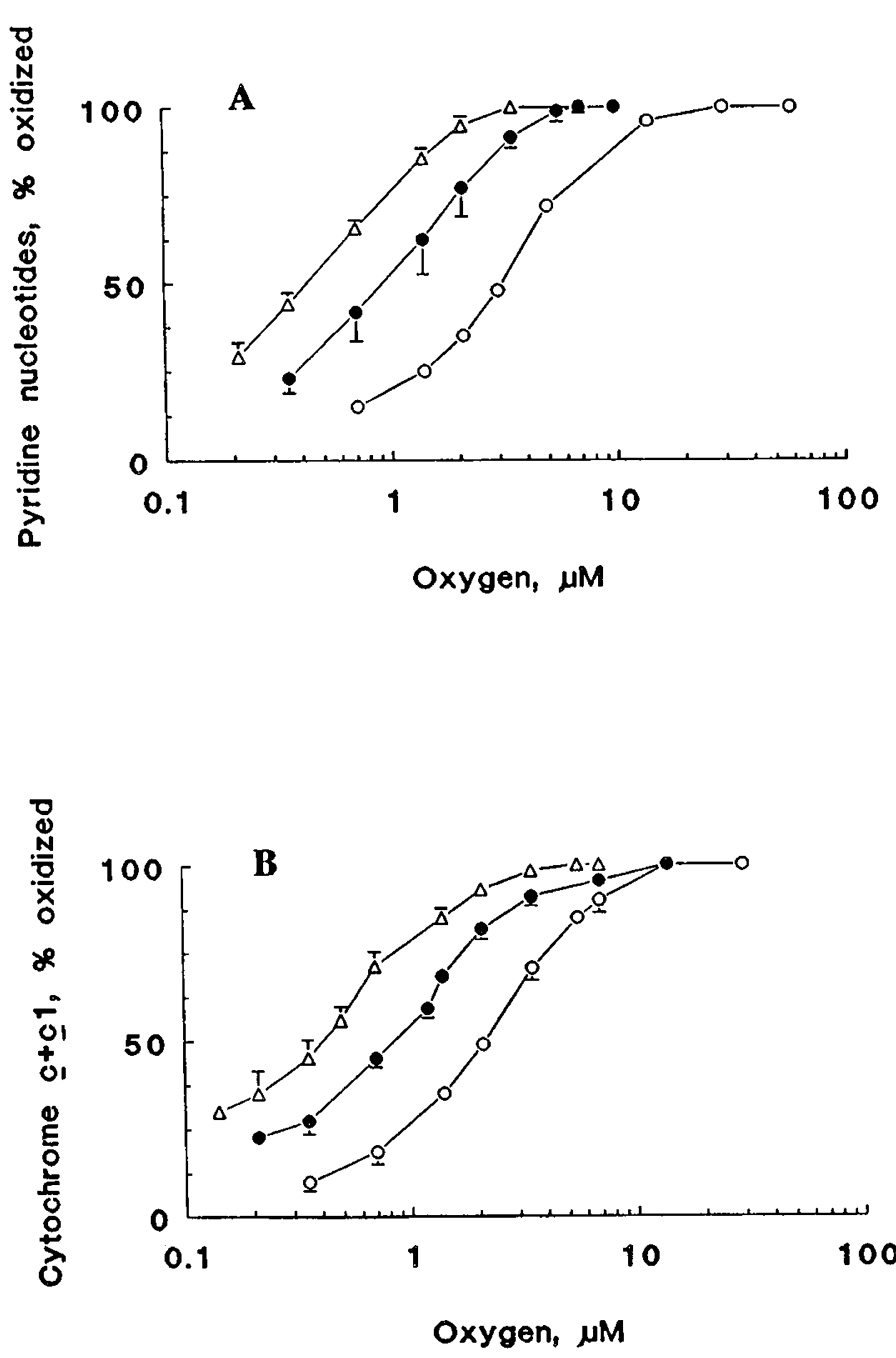

Fig. 3. $\mathrm{O}_{2}$ dependence of oxidation of pyridine nucleotides $(A)$ and cytochrome $c+c_{l}(B)$ as a function of postnatal ages. The $\mathrm{O}_{2}$ dependence of oxidation-reduction changes in pyridine nucleotides and cytochrome $c+c$, was determined in incubations $\left(1.5 \times 10^{6}\right.$ or $1.0 \times 10^{6}$ cells $/ \mathrm{mL}$ for neonatal or adult hepatocytes, respectively) containing $1.5 \mathrm{mM}$ succinate (6). Changes were measured using the wavelength pairs 340 $375 \mathrm{~nm}$ for pyridine nucleotides and 550-540 nm for cytochrome $c+$ c $"$. Results are expressed as \% oxidized calculated with respect to aerobic cells. Data given represent the mean \pm SEM of the respective number of cell preparations: for pyridine nucleotide measurements, three for neonatal and two for adult rats, and for cytochrome $c+c_{l}$, five for newborn and three for 4-d-old and adult rats. For data points without error bars, SEM was less than the size of the point.

consumption; the $\mathrm{P}_{50}$ values were decreased $(0.07 \mu \mathrm{M} \mathrm{O})$ or increased $\left(0.86 \mu \mathrm{M} \mathrm{O}_{2}\right)$, respectively, by additions of $11 \mathrm{nM}$ antimycin $A$ or $5 \mathrm{mM}$ succinate. These results suggest that, as with mitochondrial cytochromes $(6,7)$, the oxidation of reducing equivalents is responsive to substrate availability and that the $\mathrm{P}_{50}$ value is sensitive to cellular $\mathrm{O}_{2}$ consumption rates.

Direct comparison of the $\mathrm{O}_{2}$ dependence of pyridine nucleotides at different postnatal ages shows that the $\mathrm{P}_{50}$ values increase with age of the rat (Fig. $3 A$ ); the $\mathrm{P}_{50}$ values were 1.2 and $4.0 \mu \mathrm{M}$ $\mathrm{O}_{2}$, respectively, for 4-d-old and adult hepatocytes. This agedependent increase in $\mathrm{O}_{2}$ concentration required for oxidation of pyridine nucleotides paralleled the increase in cellular $\mathrm{O}_{2}$ consumption rates with age of the animals (Table 2), which would be consistent with an enhancement of cell respiration in association with postnatal increases in oxidative metabolism (15).

Similar measurements of the oxidation of mitochondrial cytochrome $c+c_{I}$ show that the age-dependent changes in $\mathrm{P}_{50}$ values occurred over the same range as that for pyridine nucleotides. The $\mathrm{P}_{50}$ oxidations were, respectively, $0.46,0.85$, and 3.7 $\mu \mathrm{M} \mathrm{O}_{2}$ for cells from newborn, 4-d-old, and adult rats (Fig. $3 B$ ). These results indicate that the developmental increases in $\mathrm{O}_{2}$ concentration required for oxidation of reducing equivalents closely parallel those required for oxidation of mitochondrial cytochromes. It is significant that the $\mathbf{P}_{50}$ value for oxidation of pyridine nucleotides is similar to the values for oxidation of cytochrome $c+c_{l}$ and other mitochrondrial cytochromes $\left(\mathrm{P}_{50}\right.$ values between 0.5 and $0.75 \mu \mathrm{M} \mathrm{O}_{2}$ ) (6), suggesting that kinetic limitation does not occur at the NADH dehydrogenase. Moreover, the correspondence of the $\mathrm{O}_{2}$ dependences of pyridine nucleotides with those of cytochromes at different postnatal ages (Fig. 3) suggests that the development of mitochondrial oxidation of reducing equivalents occurs concurrently with the development of the mitochondrial respiratory components.

\section{DISCUSSION}

The present study demonstrates that pyridine nucleotide concentration, distribution of oxidized versus reduced forms, redox ratios, and oxidation-reduction characteristics alter quantitatively during postnatal development. Because near-adult values are attained by $\mathrm{d} 8$ postpartum, the most significant changes appear to occur during the early phases of postnatal development, namely, within the first week after birth. The results show that the pyridine nucleotide status in neonatal hepatocytes differs from that in adult hepatocytes (Table I) (20) in two important respects, namely, the total concentration of pyridine nucleotides is lower and the relative reductive capacity is higher in neonatal cells. In neonatal cells, the ratio of oxidized to reduced pyridine nucleotides is $1: 1$ (Table 1 ), which is dramatically different from the 2.3:1 distribution of oxidized to reduced nucleotides in adult cells (Table 1) (20). Even when expressed relative to protein content $\left(1.1 \mathrm{mg} / 10^{6}\right.$ cells in newborn and 4-d-old, $1.35 \mathrm{mg} / 10^{6}$ cells in 8-d-old, and $1.6 \mathrm{mg} / 10^{6}$ cells in adult cells) (6), the values are not significantly different from those expressed per $10^{6}$ cells (Table 1). Thus, the age-dependent differences in pyridine nucleotide concentrations and distribution of individual oxidized and reduced forms represent true developmental changes from the newborn to the adult.

The distribution patterns of NADPH and NADH during postnatal development reflect the specific metabolic demands for 
these reducing equivalents at the different ages. The results show that, quantitatively, the NADPH levels represent $40-50 \%$ of the total pyridine nucleotides in the first $4 \mathrm{~d}$ after birth (Fig. 1). This result, together with the presence of low NADH levels, is consistent with a high requirement for NADPH for biosynthetic processes associated with the rapid growth phase in neonatal rat liver during early development $(1,14)$ and a limited oxidation of $\operatorname{NADH}(8,10,23)$. It is possible that the differences in pyridine nucleotide composition and distribution can be attributed, in part, to contribution from nonparenchymal and hematopoietic cells, which constitute a relatively large percentage, by mass, of the liver of newborn rats (1). However, the isolation and purification procedure that is used in the present study yields $\sim 90 \%$ hepatocytes; thus, the contribution from other cell types is unlikely to be quantitatively significant.

Hommes and Richters (23) have shown that the mitochondrial NADH oxidation in fetal and neonatal liver occurs predominantly via the malate-aspartate shuttle because the $\alpha$-glycerophosphate shuttle is nonoperative as a result of the absence of $\alpha$ glycerophosphate dehydrogenase in the liver mitochondria. Moreover, Papa et al. (24) have shown that the glutamate dehydrogenase activity is suppressed by a high NADPH/NADP ${ }^{+}$ ratio. These results, therefore, suggest that the oxidation of $\mathrm{NAD}^{+}$-linked substrates in neonatal cells may generally be limited, consistent with the slow ontogenic development of pyruvate dehydrogenase during the late fetal and early postnatal phases of development (9). The results further suggest that the oxidation of other substrates, such as those linked to reduced flavin-adenine dinucleotide may be quantitatively more important in these cells. In support of this thinking, we previously found that mitochondrial use of succinate is preferred during the early postnatal period $(6,7)$. The preferential use of succinate, a reduced flavinadenine dinucleotide-linked substrate, in neonatal cells may selectively spare NADH for transhydrogenation to NADPH, which can then be used for reductive biosynthetic processes. Therefore, the preferred choice of neonatal hepatocytes for succinate could provide a way to balance the requirement of NADPH for purposes of growth and differentiation with the demand for oxidizable substrates to accomodate the increase in oxidative metabolism after birth. The subsequent decrease in NADPH and increase in NADH relative to total pyridine nucleotide content with increasing age of the rat corresponds to an increase in mitochondrial oxidation of $\mathrm{NAD}^{+}$-linked substrates in adult animals $(23,25)$ and a decrease in biosynthetic processes associated with reduced tissue growth.

The age-dependent changes in pyridine nucleotide composition and distribution do not appear to be synchronized with the increases in mitochondrial respiratory activity by increased intramitochondrial adenine nucleotide pool sizes $(11-13,26,27)$ in that the time courses for these two events are different. Previous studies have shown that dramatic increases in concentrations of cellular adenine nucleotides and substantial redistribution of cytosol-to-matrix adenine nucleotides occur within hours after birth $(11-13,26,27)$. The increase in matrix total adenine nucleotide content was correlated with increases in mitochondrial pyruvate carboxylase activity in association with increases in the gluconeogenic rate of the newborn $(28,29)$. Our current results show that the attainment of adult values in composition and distribution of pyridine nucleotides occurred in several days and corresponded to a decrease in succinatedependent stimulation of respiration with increasing age of the rats (Table 2), indicating a shift in direct substrate requirement for the mitochondria. These results therefore suggest that the differences in regulation of the two nucleotide pools could be dictated by specific metabolic requirements at the different ages.

Comparison of the $\mathrm{O}_{2}$ dependence of oxidation-reduction of pyridine nucleotides in neonatal hepatocytes with those in adult cells shows that the $\mathrm{P}_{50}$ values in neonatal cells are relatively low. These results are consistent with the interpretation that mitochondria are present at a lower density and not extensively clustered in neonatal cells $(15,22,30)$. The data are also consistent with a lower $\mathrm{O}_{2}$ consumption rate in neonatal cells even in the presence of added substrate (Table 2). The similarities in $\mathrm{O}_{2}$ requirements for oxidation of pyridine nucleotides and mitochondrial cytochromes at different ages (Fig. 3) suggest that the development of mitochondrial substrate oxidation occurs in concert with that of mitochondrial respiratory apparatus even though there appears to be a lack of synchronization of the appearance of many enzyme and cytochrome systems in late fetal and early postnatal mitochondria (1-5). The remarkable postnatal changes in oxidative and reductive status of the pyridine nucleotides and the low $\mathrm{O}_{2}$ requirements for oxidation in neonatal cells suggest that these less differentiated cells have a unique metabolic demand for reducing equivalents that differs from that of adult tissues. Thus, this study suggests that the neonatal hepatocyte could provide a suitable experimental model to examine the developmental changes in various metabolic functions and regulation that are associated with changes in cellular pyridine nucleotide status.

In summary, these studies with isolated hepatocytes from neonatal rats of different ages show that the pyridine nucleotide concentrations and distribution pattern of the oxidized and reduced species in neonatal cells during early postnatal development are quantitatively different from adult cells. The relatively higher reductive capacity of neonatal hepatocytes compared with that of adult cells appears to be the result of the differences in metabolic demands for reducing power for reductive biosynthetic versus oxidative reactions and in the ability of neonatal cells to use alternate sources of fuel for oxidative purposes. Finally, studies on the oxidation-reduction of pyridine nucleotides demonstrate that reducing equivalents respond to variations in $\mathrm{O}_{2}$ concentration in a manner similar to mitochondrial cytochromes throughout postnatal development.

\section{REFERENCES}

1. Jones CT 1982 The development of the metabolism in the fetal liver. In: Jones CT (ed) Biochemical Development of the Fetus and Neonate. Elsevier Biomedical Press, Amsterdam, pp 249-286

2. Van Rossum GDV 1963 Respiration and glycolysis in liver slices prepared from rats of different foetal and post-natal ages. Biochim Biophys Act 74:15-23

3. Pollak JK, Duck-Chong CG 1973 Changes in rat liver mitochondria and endoplasmic reticulum during development and differentiation. Enzyme

4. Smith $\mathrm{CH} 1970$ Perinatal regulation of mitochondrial and cytoplasmic enzymes in rabbit liver. Pediatr Res 4:328-336

5. Jakovcic S, Haddeok J, Getz GS, Rabinowitz M, Swift H 1971 Mitochondrial development in liver of foetal and newborn rats. Biochem J 121:341-347

6. Aw TY, Jones DP 1987 Respiratory characteristics of neonatal rat hepatocytes Pediatr Res 21:492-496

7. Aw TY, Jones DP 1988 Succinate and oxygen dependence of mitochondrial function in neonatal hepatocytes. In: Lemasters JJ, Hackenbrock CR, Thurman RG, Westerhoff HV (eds) Integration of Mitochondrial Function.
Plenum Press, New York, pp 445-450

8. Berger R, Hommes FA 1975 Regulation of pyruvate metabolism in fetal rat liver. In: Hommes FA, Vanden Berg CJ (eds) Normal and Pathological Development of Energy Metabolism. Academic Press, London, pp 97-107

9. Meisanmi E, Timiras PS 1982 Normal and abnormal biochemical development of the brain after birth. In: Jones CT (ed) Biochemical Development of the Fetus and Neonate. Elsevier Biomedical Press, Amsterdam, pp 758-821

10. Cremer JE, Teal HM 1974 The activity of pyruvate dehydrogenase in rat brain during postnatal development. FEBS Lett 39:17-20

11. Aprille JR, Asimakis GK 1980 Postnatal development of rat liver mitochondria: state 3 respiration, adenine nucleotide translocase activity, and the net accumulation of adenine nucleotides. Arch Biochem Biophys 201:564-575

12. Aprille JR 1981 Net uptake of adenine nucleotides by newborn rat liver mitochondria. Arch Biochem Biophys 207:157-164

13. Rulfs J, Aprille JR 1982 Adenine nucleotide pool size, adenine nucleotide translocase activity and respiratory activity in newborn rabbit liver mito-
chondria. Biochim Biophys Acta 681:300-304

14. Snell K 1982 Protein, amino acid and urea metabolism in the neonate. In: Jones CT (ed) Biochemical Development of the Fetus and Neonate. Elsevier Biomedical Press, Amsterdam pp 651-695

15. Devirgiliis LC, Dini L, DiPierro A, Leoni S, Spagnuolo S, Steffani S 1981 An improved nonperfusion method for the isolation and purification of rat foetal and neonatal hepatocytes. Cell Mol Biol 27:687-694

16. Aw TY, Jones DP 1982 Secondary bioenergetic hypoxia. Inhibition of sulfation 
and glucuronidation reactions in isolated hepatocytes at low $\mathrm{O}_{2}$ concentration. J Biol Chem 257:8997-9004

17. Moldeus P, Hogberg J, Orrenius S 1978 Isolation and use of liver cells. Methods Enzymol 51:60-70

18. Jones DP, Thor H, Andersson BS, Orrenius S 1978 Detoxification reaction in isolated hepatocytes. Role of glutathione peroxidase, catalasem and formaldehyde dehydrogenase in reactions relating to $\mathrm{N}$-demethylation by cytochrome P-450 system. J Biol Chem 253:6031-6037

19. Jones DP, Kennedy FG 1982 Intracellular oxygen supply during hypoxia. Am J Physiol 243:C247-C253

20. Jones DP 1981 Determination of pyridine nucleotides in cell extracts by highperformance liquid chromatography. J Chromatogr 225:446-449

21. Bradford MM $1976 \mathrm{~A}$ rapid and sensitive method for the quantitation of microgram quantities of protein utilizing the principle of protein-dye binding. Anal Biochem 72:248-254

22. Jones DP 1984 Effect of mitochondrial clustering on $\mathrm{O}_{2}$ supply in hepatocytes. Am J Physiol 247:C83-C89

23. Hommes FA, Richters AR 1969 Mechanism of oxidation of cytoplasmic reduced nicotinamide adenine dinucleotides in the developing rat liver. Biol Neonate 14:359-364
24. Papa S, Tager JM, Francavilla A, de Haan EJ, Quagliariello E 1967 Control of glutamate dehydrogenase activity during glutamate oxidation in isolated ratliver mitochondria. Biochim Biophys Acta 131:14-28

25. De Vos MA, Wilmink CW, Hommes FA 1968 Development of some mitochondrial oxidase systems of rat liver. Biol Neonate 13:83-89

26. Pollak JK 1975 The maturation of the inner membrane of foetal rat liver mitochondria. An example of a positive feedback mechanism. Biochem $\mathrm{J}$ 150:477-488

27. Sutton R, Pollak JK 1978 The increasing adenine nucleotide concentration and the maturation of rat liver mitochondria during neonatal development. Differentiation 12:15-21

28. Aprille JR, Yaswen P, Rulfs $J 1981$ Acute postnatal regulation of pyruvate carboxylase activity by compartmentation of mitochondrial adenine nucleotides. Biochim Biophys Acta 675:143-147

29. Brennan WA, Aprille JR 1984 Regulation of hepatic gluconeogenesis by rapid compartmentation of mitochondrial adenine nucleotides in the newborn rabbit. Comp Biochem Physiol [B] 77:35-39

30. Jones DP 1986 Intracellular diffusion gradients of $\mathrm{O}_{2}$ and ATP. Am J Physiol 250:C663-C675 